Short Communication

\title{
THE INFLUENCE OF AERATED DRINKS ON THE BLOOD PRESSURE AND HEART RATE OF YOUNG ADULTS
}

\author{
SOMASHEKAR SHETTY1 ${ }^{*}$, NITHYA ANTHONY DASS ${ }^{2}$
}

\author{
Department of Biochemistry Melaka Manipal Medical College, Manipal Campus, Manipal Academy of Higher Education (MAHE) Manipal, \\ India 576104 \\ Email: somashekarshetty@yahoo.com
}

Received: 09 Jan 2019 Revised and Accepted: 29 Mar 2019

\section{ABSTRACT}

Objective: To study the relationship of aerated drink (soft drink) consumption on the blood pressure and heart rate of student population.

Methods: 50 medical students ( 25 male and 25 female) volunteered to participate in this study. The blood pressure and heart rate of the student was taken and recorded as initial blood pressure (pre-test, control). The student was then given $250 \mathrm{ml}$ of aerated drink. After 20 min* the blood pressure (BP) and heart rate of the student was taken once again (post-test) and the reading was recorded.

Results: The statistical analysis suggest that, there was $0.88 \pm 0.10 \mathrm{~mm} / \mathrm{Hg}$ increase in the mean arterial pressure, subsequent to the consumption of the aerated drink in the male student population and $2.85 \pm 0.18 \mathrm{~mm} / \mathrm{Hg}$ in the female student population. Similarly, $0.76 \pm 0.03 \mathrm{beats} / \mathrm{minute}$ increase in the heart rate in male population and $1.2 \pm 0.05$ beats/minute was observed in female population.

Conclusion: In our study aerated drink have not shown a significant effect on mean arterial pressure and heart rate in both males and females. Chronic consumption may have the effect on mean arterial pressure and heart rate but random consumption may not have significant effect.

Keywords: Aerated drink, Blood pressure, Heart rate

(C) 2019 The Authors. Published by Innovare Academic Sciences Pvt Ltd. This is an open access article under the CC BY license (http://creativecommons.org/licenses/by/4.0/) DOI: http://dx.doi.org/10.22159/ijpps.2019v11i5.31952

\section{INTRODUCTION}

Aerated drinks (soft drink) are becoming part and parcel of today`s lifestyle. The main factor which drives the demand of the product is taste, besides being a unique class of beverage that is mainly served as a thirst quencher. Aerated drinks are enjoyed by almost every age group in various countries, especially in fast food corners. Companies in the aerated drink industry mainly target adolescents and young adults. Some consume aerated drinks as energy drinks to gain more energy or while drinking alcohol at parties. Some admit to drinking these beverages without any particular reason or when feeling exhausted [1]. One can of this has about 10 teaspoons of sugar, 150 calories, 30 to $55 \mathrm{mg}$ of caffeine and is loaded with artificial food colours. Caffeine, if consumed in excess, may induce insomnia, increase arterial blood pressure (BP) and can later contribute to a higher risk of osteoporosis and cardiovascular diseases [2, 3]. Moreover, the high glucose content is another health hazard which potentially promotes overweight and dental caries [4]. The world is now struggling with epidemics of obesity and type 2 diabetes. One of the reasons for this is the substantial increase in the consumption of beverages that contain sucrose and caffeine. Fructose with glucose, is a product of sucrose breakdown, has been associated with such health problems as body weight gain and insulin resistance [5]. Consumption of this drinks can raise the risk of developing arterial hypertension and type 2 diabetes, while a high intake of caffeine lowers the sensitivity to insulin [6]. High economic status, hypertension, physical inactivity, stress, tea, coffee, junk foods, soft drinks and known family history are the major risk factors for type 2 diabetes mellitus [7]. Several other studies were enlightened about the effect of aerated drinks in the variations of blood pressure and heart rate. In this study, students from Melaka Manipal Medical College, Manipal Campus (MMMC) were screened for the influence of aerated drinks with respect to their blood pressure and heart rate.

50 medical students (25 male medical students and 25 female medical students) were invited to participate in this study. Ethical clearance was obtained from Kasturba Medical College (KMC), Manipal University, Institutional Ethical Committee (IEC No: $785 / 2015)$. The consent was obtained from each participant for the study. The blood pressure (BP) and heart rate of the student was taken and recorded as initial blood pressure (pre-test) using fully automatic electronic sphygmomanometer (Apollo Pharmacy, Blood pressure monitor, Model U80B) (fig. 1).

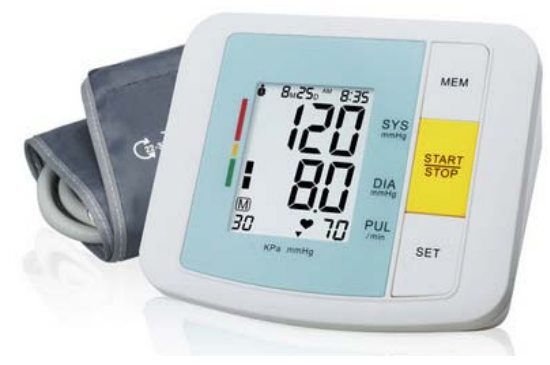

Fig. 1

The study used one of the most popular soft drinks purchased at the local market. The students were given $250 \mathrm{ml}$ of soft drink in a paper cup and asked to drink it. They were asked to rest for 20 min*. After $20 \mathrm{~min}^{*}$, the BP and heart rate was taken once again (post-test) and the reading was recorded. Results were then tabulated and mean arterial pressure was calculated. Formula for the calculation of Mean arterial pressure is-

Diastolic Pressure+(1/3 $\times$ Pulse Pressure $)$ Where, pulse pressure $=$ Systolic Pressure-Diastolic Pressure.

The statistical analysis suggest that, there was $0.88 \pm 0.10 \mathrm{~mm} / \mathrm{Hg}$ increase in the mean arterial pressure, subsequent to the consumption of the aerated drink in the male student population and $2.85 \pm 0.18 \mathrm{~mm} / \mathrm{Hg}$ in the female student population. Similarly, $0.76 \pm 0.03$ beats/minute increase in the heart rate in male population and $1.2 \pm 0.05$ beats/minute was observed in female population. Increase is slightly more in female population but it is statistically insignificant (fig. 2, 3).

In our study aerated drink have not shown a significant effect on mean arterial pressure and heart rate in both males and females. Chronic consumption may have the effect on mean arterial pressure 
and heart rate but random consumption may not have significant effect. This particular facts were proved by several researchers. These beverages are loaded with sugar (high fructose corn syrup) in the drinks. Overconsumption of fructose, particularly in the form of soft drinks, is increasingly recognized as a public health concern. The exact mechanism of fructose-induced hypertension is unknown. Experimental evidence suggests that fructose stimulates the sympathetic nervous system, reduces renal sodium and fluid excretion and increases serum uric acid levels, which then leads to a direct vascular effect to limit nitric oxide or to activate the reninangiotensin-aldosterone system. Ingestion of glucose and fructose drinks is characterized by specific hemodynamic responses. In particular, fructose ingestion elicits an increase in blood pressure that is probably mediated by an increase in cardiac output without compensatory peripheral vasodilatation [8]. Gokul and

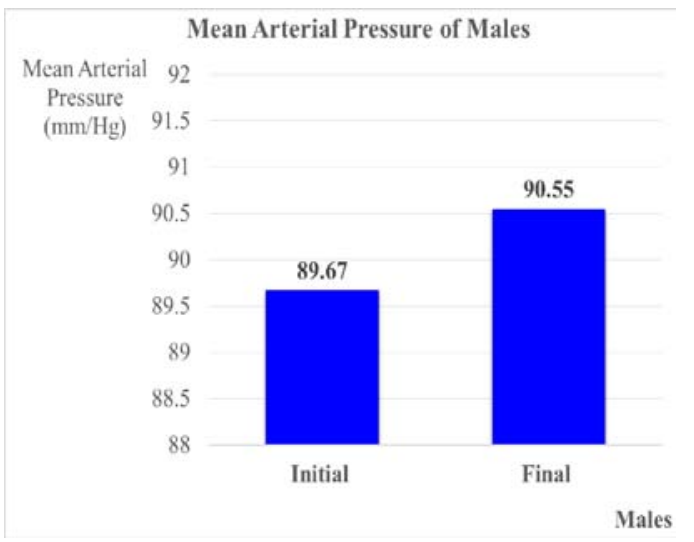

Fig. 2

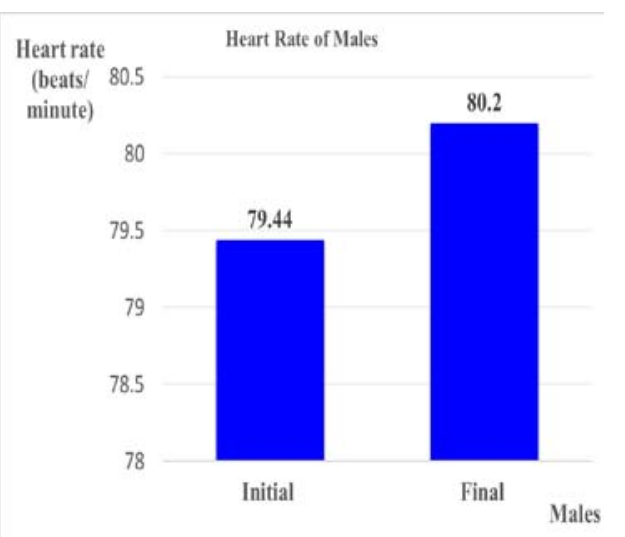

others were conducted the questionnaire study on tooth sensitivity among residential university students in Chennai. It was interesting to note that students who had soft drinks regularly also play a good role in tooth sensitivity due to enamel erosion from bad brushing habits. Soft drinks should be avoided to the highest extent and treatment for sensitivity should be taken promptly [9]. These beverages are also often loaded with preservative sodium benzoate, which can also contribute in increasing the blood pressure.

Children and adolescents with high intakes of carbonated beverages could be at increased risk of hypertension, metabolic syndrome and abdominal obesity. Education/awareness on ill effects of aerated drinks, fast foods particularly changes in BP and heart rate as well as the importance of nutrition during the adolescent phase should be emphasized in future programmes.

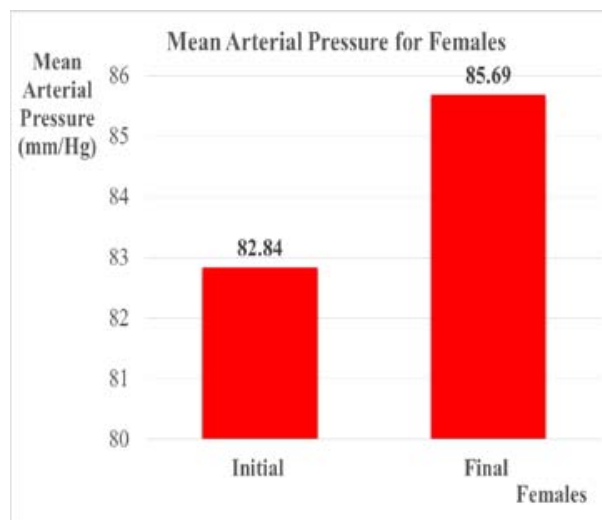

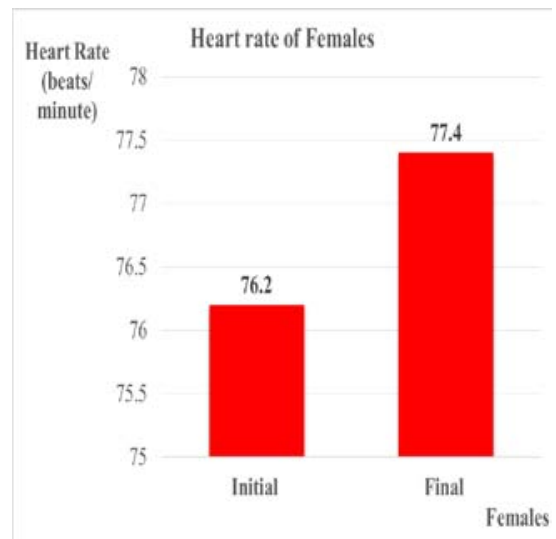

Fig. 3

\section{AUTHORS CONTRIBUTIONS}

Ms. Nithya Anthony Dass conducted the experiment. Dr. Somashekar Shetty helped in designing and conducting the experiment and prepared the manuscript.

\section{CONFLICT OF INTERESTS}

The authors declare that there are no conflicts of interest.

\section{REFERENCES}

1. Nowak D, Jasionowski A. Analysis of the consumptions of caffeinated energy drinks among polish adolescents. Int J Environ Res Public Health 2015;12:7910-21.

2. Temple JL. Caffeine use in children: what we know, what we have left to learn, and why we should worry. Neurosci Biobehav Rev 2009;33:793-806.
3. Cooper C, Atkinson EJ, Wahner HW, O’Fallon WM, Riggs BL, Judd HL, et al. Is caffeine consumption a risk factor for osteoporosis? J Bone Miner Res 1992;7:465-71.

4. Marks R. Energy drinks: a potentially overlooked obesity correlate. Adv Obes Weight Manag Control 2015;2:00019.

5. Rush E, Schulz S, Obolonkin V, Simmons D, Plank L. Are energy drinks contributing to the obesity epidemic? Asia Pac J Clin Nutr 2006;15:242-4.

6. Monnard C, Jean Pierre M, Grasser K. Cerebro-and cardiovascular responses to energy drink in young adults: Is there a gender effect? Front Physiol 2016;346:1-11.

7. Sivaprasad P, Siddhartha N, Charan V, Naveenbabu K, Siva RC, Ravindrababu P. A prospective study on the assessment of risk factors for type 2 diabetes mellitus in outpatients department of a south Indian tertiary care hospital: a case-control study. Asian J Pharm Clin Res 2016;9:300-4. 
8. Brown CM, Dulloo AG, Yepuri G, Montani JP. Fructose ingestion acutely elevates blood pressure in healthy young humans. Am J Physiol Regul Integr Comp Physiol 2008;294:730-7.
9. Gokul G, Abilasha S. Tooth sensitivity among residential university students in Chennai. Asian J Pharm Clin Res 2016;9:63-5. 